\title{
Chronic Kidney Disease in Sub-Saharan Africans: A Study of 462 Patients
}

\author{
Mbengue Mansour $^{1 *}$, Ba Djenaba², Lemrabott Tall Ahmed ${ }^{2}$, Cissé Mouhamadou Moustapha ${ }^{3}$, \\ Niang Abdou ${ }^{1}$
}

${ }^{1}$ Department of Nephrology, Dalal Jamm University Hospital, Dakar, Senegal

${ }^{2}$ Department of Nephrology, Aristide Le Dantec University Hospital, Dakar, Senegal

${ }^{3}$ Department of Nephrology, El Hadji Amadou Sakhir Ndiéguéne Hospital, Thiés, Senegal

Email: *mansourmbengue92@gmail.com

How to cite this paper: Mansour, M., Djenaba, B., Ahmed, L.T., Moustapha, C.M. and Abdou, N. (2021) Chronic Kidney Disease in Sub-Saharan Africans: A Study of 462 Patients. Open Journal of Nephrology, 11, 114-122.

https://doi.org/10.4236/ojneph.2021.111009

Received: December 3, 2020

Accepted: March 28, 2021

Published: March 31, 2021

Copyright (C) 2021 by author(s) and Scientific Research Publishing Inc. This work is licensed under the Creative Commons Attribution International License (CC BY 4.0).

http://creativecommons.org/licenses/by/4.0/

\begin{abstract}
Chronic kidney disease is a global public health problem due to its increasing prevalence as well as its main risk factors such as hypertension and diabetes. However, in Africa, few studies have been done on chronic kidney disease. The aim of our study is to describe the epidemiological, clinical, paraclinical and therapeutic aspects of chronic kidney disease. It was a retrospective and descriptive study carried out from the first of January 2004 to the $31^{\text {st }}$ of December 2013 at Principal hospital in Dakar. Records of any patient aged 18 and over with chronic kidney disease were included. Chronic kidney disease was defined according to the KDIGO 2012 recommendations. Among the 8873 patient records used during our study, 462 presented with chronic kidney disease, which was a hospital prevalence of 5.2\%. The sex ratio was 1.61 . The mean age of the patients was $58.37 \pm 19.97$ years. There were $75.32 \%$ of the patients who were aged 50 and over. The mean serum creatinine was $49.14 \pm$ 56.83. The mean glomerular filtration rate was $27.47 \pm 19.86 \mathrm{ml} / \mathrm{min} / 1.73 \mathrm{~m}^{2}$. Chronic renal failure was diagnosed in $92 \%$ of patients, including $34.9 \%$ in the end-stage of the renal disease. The mean proteinuria was $3.07 \pm 4.92 \mathrm{~g} / 24$ h. Leukocyturia was present in $34.17 \%$ of patients. Hematuria was present in $25 \%$ of patients. Hypertension and diabetes were the most common causes, found in $61.25 \%$ and $35.93 \%$ of patients, respectively. Hemodialysis was performed in 49 patients. Peritoneal dialysis was performed in 2 patients. One patient had undergone a kidney transplant. This study establishes the relatively high prevalence of chronic kidney disease and its risk factors including hypertension and diabetes. It also reveals the late diagnosis of chronic kidney disease in our patients.
\end{abstract}

\section{Keywords}

Chronic Kidney Disease, Hypertension, Diabetes 


\section{Introduction}

Chronic kidney disease (CKD) is a global public health problem due to its increasing prevalence as well as its major risk factors which are hypertension and diabetes. Therefore, it contributes significantly to morbidity and mortality and the reduction in life expectancy. Mortality and morbidity are significant because the most affected patients do not access renal replacement therapy. In 2015, more than one over 10 adults was suffering from CKD and more than 600 million worldwide [1]. In 2013, a study estimated that 956,200 deaths worldwide were directly attributable to CKD, which was an increase of $134.6 \%$ from 1990 [2]. However, the data available on CKD in countries with limited resources are patchy and come from a few isolated studies [3]. A recent study in Senegal showed CKD prevalence of $4.9 \%$ [4]. This study was carried out with the aim of determining the epidemiological, clinical, paraclinical and therapeutic aspects in patients with CKD.

\section{Patients and Methods}

This was a retrospective and descriptive study carried out over a period of ten years, extending from the first of January 2004 to the $31^{\text {st }}$ of December 2013 at Principal Hospital in Dakar. Records of any patient aged 18 and over with CKD were included. The CKD was defined according to the 2012 KDIGO (kidney disease improving global outcomes) recommendations [5]. Patients with acute renal failure or any incomplete or inoperable patient records were not included in the study. Sociodemographic, clinical and paraclinical characteristics were studied. Glomerular filtration rate (GFR) was calculated according to the MDRD (Modification of diet in Renal Disease) formula [6]. Data were collected from patient medical records using pre-established forms. The data were entered and analyzed using a questionnaire developed with the Epi info 7 software and analyzed with the SPSS version 18 software.

\section{Results}

During our study period, 8873 records were collected, among which 462 presented a CKD, for a hospital prevalence of 5.2\%. There were 285 men and 177 women, for a sex ratio of 1.61 . The mean age of the patients was $58.37 \pm 19.97$ years (Table 1$)$. There were $348(75.32 \%)$ patients who were aged 50 years and older (Figure 1). Twenty-seven patients (5.85\%) had a history of herbal medicine use. The reasons for consultation were mainly represented by edema of the lower limbs (25.10\%), vomiting (13.63\%) and dyspnea (22.29\%) (Table 2). Three hundred and eighteen patients (68.83\%) had systolic hypertension. Two hundred and seventy patients $(58.44 \%)$ had diastolic hypertension. The mean blood urea level was $1.18 \mathrm{~g} / \mathrm{L} \pm 0.95$. The mean serum creatinine was $49.14 \mathrm{mg} / \mathrm{L} \pm 56.83$. The mean GFR was $27.47 \pm 19.86 \mathrm{ml} / \mathrm{min} / 1.73 \mathrm{~m}^{2}$. Chronic renal failure was diagnosed in $92 \%$ of patients, including $34.9 \%$ in the end-stage of the renal disease (ESRD) (Figure 2). There were $82.8 \%$ of our patients who had anemia. Hypocalcaemia was observed in $51.62 \%$ of patients. Hyperphosphatemia was present in $48.37 \%$ of 
Table 1. Demographical and clinical characteristics of participants (Data are expressed as mean \pm standard deviation or number and percentage).

\begin{tabular}{|c|c|}
\hline & Mean and percentages \\
\hline Age (years) & $58.37 \pm 19.97$ \\
\hline Sex ratio (men/women) & $1.61(285 / 177)$ \\
\hline Systolic hypertension (\%) & 68.39 \\
\hline Diastolic hypertension (\%) & 58.44 \\
\hline Obesity (\%) & $33 \%$ \\
\hline Mean blood urea $(\mathrm{g} / \mathrm{L})$ & $1.18 \pm 0.95$ \\
\hline Mean serum creatinine $(\mathrm{mg} / \mathrm{L})$ & $49.14 \pm 56.83$ \\
\hline Mean eGFR $\left(\mathrm{ml} / \mathrm{min} / 1.73 \mathrm{~m}^{2}\right)$ & $27.47 \pm 19.86$ \\
\hline Anemia (\%) & 82.8 \\
\hline Hypocalcaemia (\%) & 51.62 \\
\hline Hyperphosphatemia (\%) & 48.37 \\
\hline Hyperkalaemia (\%) & 47.8 \\
\hline Hyponatremia (\%) & 30.39 \\
\hline Total hypercholesterolemia (\%) & 76.5 \\
\hline LDL hypercholesterolemia (\%) & 76.5 \\
\hline Hypertriglyceridemia (\%) & 23.96 \\
\hline HDL dyslipidemia (\%) & 31.9 \\
\hline Hyperuricemia (\%) & 76.44 \\
\hline mean proteinuria $(\mathrm{g} / 24 \mathrm{~h})$ & $3.07 \pm 4.92$ \\
\hline Leukocyturia (\%) & 34.17 \\
\hline Hematuria (\%) & 25 \\
\hline
\end{tabular}

eGFR = estimated glomerular filtration rate according to 4-variables MDRD equation; HDL = Hight density lipoproteins; LDL = Low density lipoproteins.

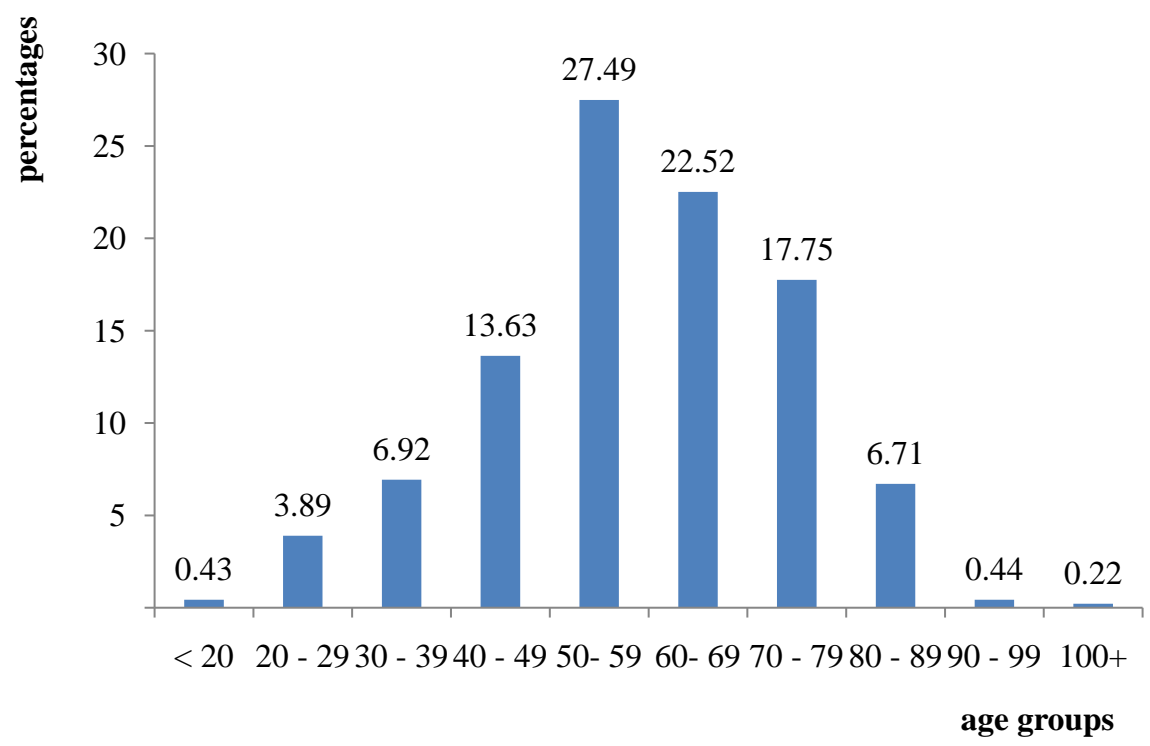

Figure 1. Distribution of patients according to age groups. 
Table 2. The different reasons for consultation.

\begin{tabular}{cc}
\hline Functional signs & Number of patientsn (\%) \\
Edema & $116(25.10)$ \\
Nausea & $12(2.59)$ \\
Vomiting & $63(13.63)$ \\
Haematemesis & $4(0.86)$ \\
Pollakiuria & $17(3.67)$ \\
Haematuria & $2(0.43)$ \\
Dyspnea & $103(22.29)$ \\
Hiccups & $11(2.38)$ \\
Pruritus & $13(2.81)$ \\
Other signs & $87(18.83)$ \\
\hline
\end{tabular}

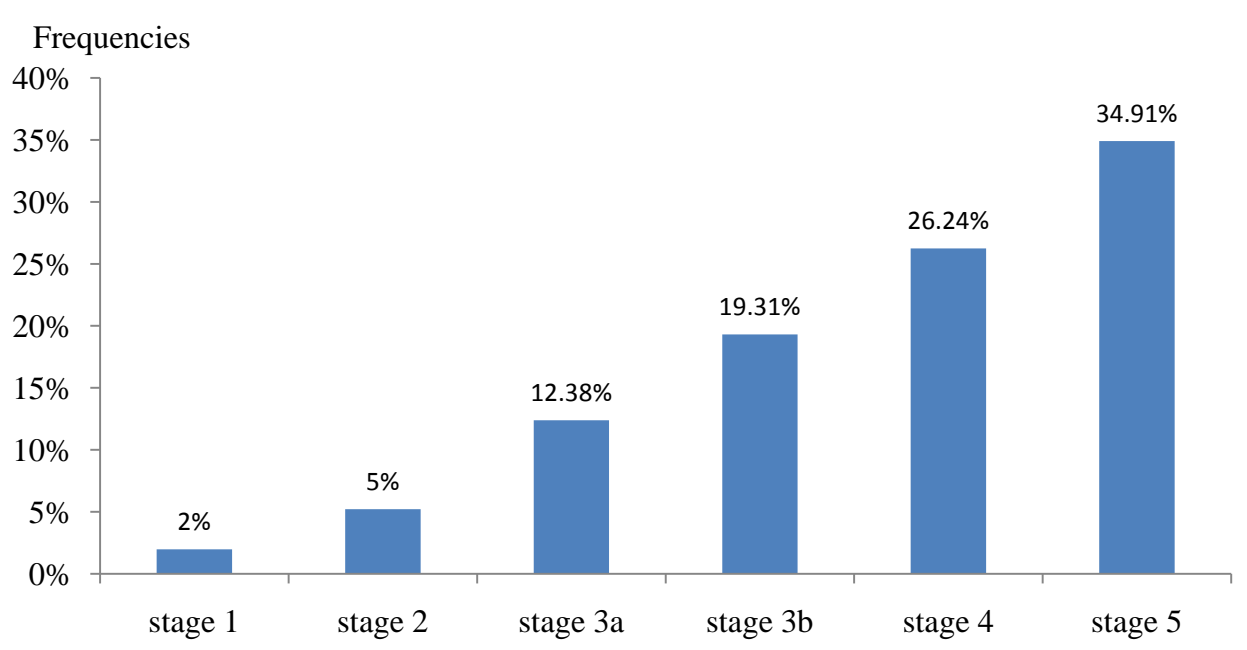

Figure 2. Distribution of patients according to stage of CKD.

patients. Hyperkalaemia was present in $47.8 \%$ of patients. Hyponatremia was present in $30.39 \%$ of patients. Hypercholesterolemia was present in $55.3 \%$ of patients. LDL hypercholesterolemia was present in $76.5 \%$ of patients. Hypertriglyceridemia was present in $23.96 \%$ of patients. HDL dyslipidemia was present in $31.9 \%$ of patients. Hyperuricemia was present in $76.44 \%$ of patients. The mean proteinuria was $3.07 \pm 4.92 \mathrm{~g} / 24 \mathrm{~h}$. Leukocyturia was present in $34.17 \%$ of patients. Hematuria was present in $25 \%$ of patients. Obesity was found in $33 \%$ of the patients. Smoking was noted in $6 \%$ of patients. Hypertension and diabetes were the most common causes, found in 283 patients $(61.25 \%)$ and 166 patients (35.93\%), respectively (Table 3 ). Kidney biopsy was indicated and performed in 23 patients, 10 of whom presented with focal segmental hyalinosis. Hemodialysis was performed in 49 patients. The mean duration of the sessions was $3.83 \pm 0.44$ hours with extremes of 2 and 4 hours. Peritoneal dialysis was performed in 2 patients. One patient had undergone a kidney transplant. 
Table 3. Causes of CKD in other studies.

\begin{tabular}{cc}
\hline Causes & Number of patients N =462 (\%) \\
\hline Hypertension & $214(46.32)$ \\
Diabetes & $97(20.99)$ \\
Mixed nephropathy (Hypertension et Diabetes) & $69(15.00)$ \\
Lupus nephritis & $2(0.43)$ \\
HIV & $1(0.21)$ \\
Focal segmental glomerulosclerosis & $10(2.16)$ \\
Membranous nephropathy & $12(2.59)$ \\
Amyloidosis & $8(1.72)$ \\
Minimal change disease & $4(0.86)$ \\
Obstructive uropathy & $3(0.65)$ \\
Autosomal dominant polycystic kidney disease & $24(5.19)$ \\
Hemopathy & $4(0.86)$ \\
Urinary lithiasis & $6(1.29)$ \\
undetermined & $8(1.73)$
\end{tabular}

\section{Discussion}

In the world, the prevalence of $\mathrm{CKD}$ is estimated at $10 \%$ but there are many variations between countries [7]. In sub-Saharan Africa, the epidemiology of CKD in the general population is difficult to estimate probably due to possible confusion caused by the heterogeneity of the populations studied, design and methods used to define CKD. By comparing our study with the other studies presented in Table 4, we see that the prevalence of CKD varies from one country to another and within the same country [4] [8]-[14]. In our study, the mean patient age was $58.37 \pm 19.97$ years and more than $70 \%$ of our patients were over 50 years old. Our study is consistent with results found in other studies. This could be explained on the one hand by the physiological decline of GFR which is observed in these advanced ages. This is currently even a topic of discussion because it leads some authors to think about redefining CKD in older ages. On the other hand, improvement in life expectancy of the population could also explain this predominance of CKD in subjects over 50 years of age [15].

Hypertension (61.25\%) and diabetes (35.93\%) were the two major risk factors associated with CKD in our series. Studies done in several countries had also found hypertension to be the leading cause of CKD [16]. This is the case of studies that were done in Cameroon and the United States where hypertension was found in $84.6 \%$ [17] and $86.1 \%$ [18] respectively. This high frequency of hypertension can be explained by behavioral changes namely smoking, sedentary lifestyle, an unsuitable diet (high in salt and fat) [16]. Hypertension in general is more common in black people due to the genetic predisposition linked to the presence of a polymorphism in the Apol 1 gene which codes for apolipoprotein 1 
Table 4. prevalence of CKD in other studies.

\begin{tabular}{cc}
\hline Studies & Prevalence \\
\hline NHANES III (USA) [8] & 11 \\
KEEP (USA) [9] & 27.2 \\
NEOERICA (UK) [8] & 11 \\
AusDiab (Australie) [8] & 10 \\
Pekin (Chine) [10] & 13 \\
SEEK (India) [11] & 17.2 \\
Norway [12] & 10.2 \\
Saint Louis (Senegal) [4] & 4.9 \\
Ghana [13] & 13.2 \\
Kinshasa [11] & 12.4 \\
Gueoul (Senegal) [14] & 36.5 \\
Our study & 5.2 \\
\hline
\end{tabular}

[19]. Hypertension is a risk factor for progression associated with CKD. And this has been reported in the studies done in Morocco [20], Lebanon [21] and Germany [22]. The kidney, which is often the cause of hypertension, can in turn be a victim of the latter through its repercussions (fibrous endarteritis and arteriosclerosis). As a result, hypertension is a factor in the progression of CKD. When transmitted to the glomerular capillaries, it aggravates intraglomerular hypertension and precipitates the development of CKD. This transmission is facilitated by the almost constant vasodilation of the afferent arteriole. Administration of antihypertensive drugs to animals with nephron reduction and arterial hypertension to a greater or lesser extent decreases glomerular sclerosis and the progression of CKD [23]. In our study, diabetes was found in $35.93 \%$ of cases. These results were similar to those found in Morocco (41.5\%) and higher than results previously found in Senegal (12.7\%) and Nigeria (5.9\%) [4] [24]. The increase in the prevalence of diabetes in developing countries seems to be explained by the rapid urbanization which is associated with a more sedentary lifestyle and the prevalence of obesity which is $33.9 \%$ in our work.

In our study, patients were diagnosed with CKD late. In fact, $92 \%$ of patients were diagnosed with chronic renal failure, including $34.9 \%$ with ESRD. The challenge in our countries must be a diagnosis at the early stages, especially in patients at risk, particularly hypertensive and diabetic patients.

\section{Conclusion}

This study establishes the relatively high prevalence of CKD and its risk factors including hypertension and diabetes. It also reveals the late diagnosis of chronic kidney disease in our patients. Developing action plans for the prevention of CKD and its early diagnosis would be beneficial for better health of the popula- 
tion. However, these data cannot be extrapolated to the general population as this is a retrospective study limited to one establishment.

\section{Statement of Ethics}

All patient information was anonymised and the written consent for publication of the study was obtained from the patients. The research was conducted ethically in accordance with the World Health Association Declaration of Helsinki and was approved by the local ethics committee.

\section{Funding Sources}

This research received no specific grant from any funding agency in the public, commercial, or not-for-profit sectors.

\section{Author Contributions}

Mansour Mbengue reviewed the literature and wrote the first draft of the manuscript. All authors reviewed and edited the manuscript and approved the final version of the manuscript.

\section{Limitations}

The retrospective design of our study represents a limitation. Kidney function was not measured 3 months later to ascertain chronicity of the disease and to roll out acute kidney injuries.

\section{Conflicts of Interest}

The authors have no conflicts of interest to declare.

\section{References}

[1] Fondation du rein (2015) Dossier de presse de la journée mondiale du rein Mars 2015. [Enligne]. http://www.fondation-du-rein.org

[2] Mills, K.T., Xu, Y., Zhang, W., Bundy, J.D., Chen, C.-S., Kelly, T.N., et al. (2015) A Systematic Analysis of World-Wide Population-Based Data on the Global Burden of Chronic Kidney Disease in 2010. Kidney International, 88, 950-957. https://doi.org/10.1038/ki.2015.230

[3] Bamgboye, E.L. (2006) End-Stage Renal Disease in Sub-Saharan Africa. Ethnicity \& Disease, 16, S2-5-S2-9.

[4] Seck, S.M., Doupa, D. and Gueye, L. (2014) Enquête de prévalence de la maladie rénale chronique dans la région Nord du Sénégal. Pan African Medical Journal, 18, 307. https://doi.org/10.1016/j.nephro.2014.07.128

[5] Levin, A., Stevens, P.E., Bilous, R.W., Coresh, J., De Francisco, A.L.M., De Jong, P.E., et al. (2013) Kidney Disease: Improving Global Outcomes (KDIGO) CKD Work Group. KDIGO 2012 Clinical Practice Guideline for the Evaluation and Management of Chronic Kidney Disease. Kidney International, 3, 1-150.

[6] (2012) Kidney Disease Improval Global Outcomes KDIGO Clinical Practice Guideline for Anemia in Chronic kidney disease. Kidney International, 


\section{2, 288-291.}

[7] James, M.T., Hemmelgarn, B.R. and Tonelli, M. (2010) Early Recognition and Prevention of Chronic Kidney Disease. Lancet, 375, 1296-1309. https://doi.org/10.1016/S0140-6736(09)62004-3

[8] Nahas, M.E.L. (2005) The Global Challenge of Chronic Kidney Disease. Kidney International, 68, 2918-2929. https://doi.org/10.1111/j.1523-1755.2005.00774.x

[9] Jurkovitz, C.T., Qiu, Y., Wang, C., Gilbertson, D.T. and Brown, W.W. (2008) The Kidney Early Evaluation Program (KEEP): Program Design and Demographic Characteristics of the Population. American Journal of Kidney Diseases, 51, S3-S12. https://doi.org/10.1053/j.ajkd.2007.12.022

[10] Zhang, L., Wang, F., Wang, L., Wang, W., Liu, B., Liu, J., et al. (2012) Prevalence of Chronic Kidney Disease in China: A Cross-Sectional Survey. Lancet, 379, 815-822. https://doi.org/10.1016/S0140-6736(12)60033-6

[11] Singh, A.K., Farag, Y.M., Mittal, B.V., Karai Subramanian, K., Ram Keithi Reddy, S., Acharya, V.N., et al. (2013) Epidemiology and Risk Factors of Chronic Kidney Disease in India-Results from the SEEK (Screening and Early Evaluation of Kidney Disease) Study. BMC Nephrology, 14, Article No. 114.

https://doi.org/10.1186/1471-2369-14-114

[12] Sumaili, E.K., Krzesinski, J.M., Cohen, E.P. and Nseka, N.M. (2010) Epidemiology of Chronic Kidney Disease in the Democratic Republic of Congo: Review of Cross Sectional Studies from Kinshasa, the Capital. Néphrologie \& Thérapeutique, 6, 232-239. https://doi.org/10.1016/j.nephro.2010.03.008

[13] Eastwood, J.B., Kerry, S.M., Plange-Rhule, J., Micah, F.B., Antwi, S., Boa, F.G., Banerjee, D. and Cappuccio, F.P. (2010) Assessment of GFR by Four Methods in Adults in Ashanti, Ghana: The need for an eGFR Equation for Lean African Populations. Nephrology Dialysis Transplantation, 25, 2178-2187. https://doi.org/10.1093/ndt/gfp765

[14] Faye, M., Lemrabott, A.T., Cissé, M., Fall, K., Keita, Y., Ngaide, A.A., et al. (2017) Prevalence and Risk Factors of Chronic Kidney Disease in an African Semi-Urban Area: Results from a Cross-Sectional Survey in Gueoul, Senegal. Saudi Journal of Kidney Disease and Transplantation, 28, 1389-1396.

https://doi.org/10.4103/1319-2442.220878

[15] Steven, V.D.V., Akinyi, H., Oti, S., et al. (2013) African Population and Health Research Center 2013. [En ligne]. http://www.carmma.org/

[16] Tostivint, I. (2010) Comment ralentir la dégradation de la fonction rénale chez le patient insuffisant rénal. In: Deray, G. and Bitker, M.-O., Eds., Séminaire d'uro-néphrologie, XXXVI ème série 2010, Groupe hospitalier Pitié-Salpêtrière Paris, 23-24.

[17] Kaze-Folefack, F., Nono, A., Halle, M.P. and Ashuntantang, G. (2013) Sévérité et contrôle de l'hypertension artérielle au cours de la maladie rénale chronique au Cameroun. La Revue Médicale de Madagascar, 3, 318-323

[18] Madhav, V.R., Yang, Q., Changchun, W. and Bakris, G. (2008) Hypertension and CKD: Kidney Early Evaluation Program (KEEP) and National Health and Nutrition Examination Survey (NHANES), 1999-2004. American Journal of Kidney Diseases, 51, S30-S37. https://doi.org/10.1053/j.ajkd.2007.12.012

[19] Larsen, C.P., Beggs, M.L., Saeed, M. and Walker, P.D. (2013) Apolipoprotein L1 Risk Variants Associate with Systemic Lupus Erythematosus-Associated Collapsing Glomerulopathy. Journal of the American Society of Nephrology, 24, 722-725. https://doi.org/10.1681/ASN.2012121180 
[20] Cordonnier, D., Corticelli, P., Maynard, C., Halimi, S. and Pinel, N. (1994) Nephropathies diabétiques. EMC (Éditions Médicales Elsevier SAS) Néphrologie, 18-066-P-10.

[21] Mount, D.B. and Yu, A.S.L. (2008) Transport of Inorganic Solutes: Sodium, Chloride, Potassium, Magnesium, Calcium and Phosphate. In: Brenner, B.M. and Levine, A.S., Eds., Brenner and Rector's The Kidney, Saunders Elsevier, Philadelphia, 156-200.

[22] Olson, J.L. and Laszik, Z.G. (2007) Diabetic Nephropathy. In: Jennette, J.C., Oison, J.L., Schwartz, M.M. and Silva, F.G., Eds., Heptinstall s Pathology of the Kidney, 6th Edition, Lippincott Williams \& Wilkins, Philadelphie, 803-852.

[23] Combe, C. and Kourilsky, O. (2014) Maladie rénale chronique: Chronic Kidney Disease. In: Kanfer, A., Kourilsky, O., Peraldi, M.N. and Christian Combe, C., Eds., Néphrologie et troubles hydro électrolytiques, Elsevier Masson, Paris, 279-334. https://doi.org/10.1016/B978-2-294-73759-6.00014-6

[24] Ulasi, I.I., Ijoma, C.K., Onodugo, O.D., et al. (2013) Towards Prevention of Chronic Kidney Disease in Nigeria: A Community-Based Study in Southeast Nigeria. Kidney International, 3, S195-S201. 